\title{
Changes in disability-free life expectancy in Canada between 1994 and 2007
}

\author{
Scott Mandich \\ Rachel Margolis ${ }^{1}$
}

\begin{abstract}
Life expectancy at birth continues to increase in Canada, reaching 81.2 years in 2009. Knowing whether these older years are healthy or disabled is critical for policymakers. We examine changes in disability-free life expectancy for men and women in Canada in 1994 and 2007 using the Sullivan method. We find that increases in life expectancy for men were due to a moderate increase in healthy years and a larger increase in disabled years. The increases in life expectancy for women were driven almost completely by increases in disabled years, suggesting an "expansion of morbidity" among women.
\end{abstract}

Keywords: Disability, mortality, morbidity, Canada.

\section{Résumé}

Lsespérance de vie à la naissance continue draugmenter au Canada, pour atteindre 81,2 années en 2009. Savoir si ces années sont passés en bonne santé ou en incapacité est essentiel pour les décideurs. Nous utilisons la méthode Sullivan pour examiner lévolution de l' espérance de vie sans incapacité des hommes et des femmes au Canada entre 1994 et 2007. Nous constatons que laugmentation de lespérance de vie des hommes était due à une hausse modérée des années en bonne santé et une augmentation plus importante dans les années en incapacité. Les augmentations de lespérance de vie pour les femmes sont presque entièrement dû a des augmentations des années à mobilité réduite, ce qui suggère une «expansion de la morbidité» chez les femmes.

Mots-clés : Incapacité, mortalité, morbidité, Canada.

\section{Introduction}

Life expectancy continues to increase in Canada, reaching 79.0 years for men and 83.4 years for women in 2009 (Human Mortality Database 2013). As the population ages and large cohorts begin to reach older age, it is crucial for policymakers to know whether these older years are characterized by health or disability (Ibbott et al. 2006).

\footnotetext{
1. Scott Mandich, Department of Sociology, Western University, London ON; and corresponding author Rachel Margolis, Department of Sociology, Western University, London ON N6A 5C2. Email: rachel.margolis@uwo.ca.
} 
Mandich and Margolis: Changes in disability-free life expectancy in Canada between 1994 and 2007

Understanding trends in both mortality and morbidity is important because even though life expectancy is increasing, trends in morbidity do not always mirror those of mortality. The theoretical debate on the competing nature of morbidity and mortality has three lines of argument. The first is a pessimistic position, which argues that improvements in mortality will be accompanied by an "expansion of morbidity" (Gruenberg 1977; Kramer 1980; Olshansky et al. 1991). If mortality decline reflects only a decline in the mortality rate due to chronic diseases but not the incidence of chronic illnesses, then people will live longer but will do so with chronic illnesses (Gruenberg 1977; Kramer 1980). This framework suggests that greater life expectancy will result in more severe chronic illnesses during the years that are gained. A second and more optimistic perspective is that increases in life expectancy may be accompanied by the addition of healthy, disability-free years, if morbidity is "compressed" into a shorter period of time at the end of life (Fries 1980). A third, more moderate perspective is that mortality decline leads to an increase in the incidence of mild, but not severe, chronic conditions (Manton 1982).

Disability-free life expectancy (DFLE) is the most commonly used measure of population health that takes into account both morbidity and mortality (Jagger et al. 2006). Its estimation produces results that can speak to the debate about whether there are tradeoffs between mortality and morbidity. Sullivan's method is the most widely used method to estimate disability-free life expectancy. This method divides the total number of person-years lived, which is obtained from the period life table, into disability and disability-free life expectancy, based on the proportion disabled, which is obtained from a cross-sectional survey. Sullivan's method has been used to study DFLE for many national populations, for example by the World Health Organization (Musgrove et al. 2000) and the Global Burden of Disease Study (Murray and Lopez 1996). It has also been used to study changes over time (Bronnum-Hansen et al. 2004; Crimmins et al. 1989; Doblhammer and Kytir 2001; Graham et al. 2004; Robine and Michel 2004; Roberge et al. 1999; Van de Water et al. 1996).

In this paper, we examine changes in disability-free life expectancy for men and women in Canada from 1994 to 2007. We first examine whether the prevalence of disability changed among adults over this period. Then we examine whether the increase in length of life is characterized by increasing or decreasing disability-free life expectancy. Although the length of life has increased, it is important to determine whether "quality" of life also increased. Are Canadians living longer, healthier lives or are they living longer lives but in poor health?

\section{Trends in life expectancy and healthy life expectancy}

Life expectancy in Canada for men and women increased dramatically during the twentieth century and into the twenty-first century. Figure 1 shows how life expectancy for men and women has increased from 1921 to 2009. In 1921, life expectancy was 58.2 years for women and 56.0 years for men. In 2009, life expectancy for women was 83.4 years and for men was 79.0 years. Canadians are living longer than ever before.

Most studies of disability-free life expectancy in Canada have used cross-sectional data, providing an overview at one point in time but leaving us unable to examine changes over time (Bélanger et al. 2008; Mayer et al. 2002; Statistics Canada 2001). Other studies have examined this topic using related measures and methods (Carrière and Légaré 2000; Loukine et al. 2002; Manuel et al. 2002; Mathers et al. 2002; Statistics Canada 2002; Wolfson 1996). Moreover, existing studies use various measures of disability because they draw on different data sources, making it difficult to compare across studies or see a trend. Some studies focus on disability-free life expectancy (Bélanger et al. 2008; Mayer et al. 2002; Statistics Canada 2001), while others use disability-adjusted life expectancy 

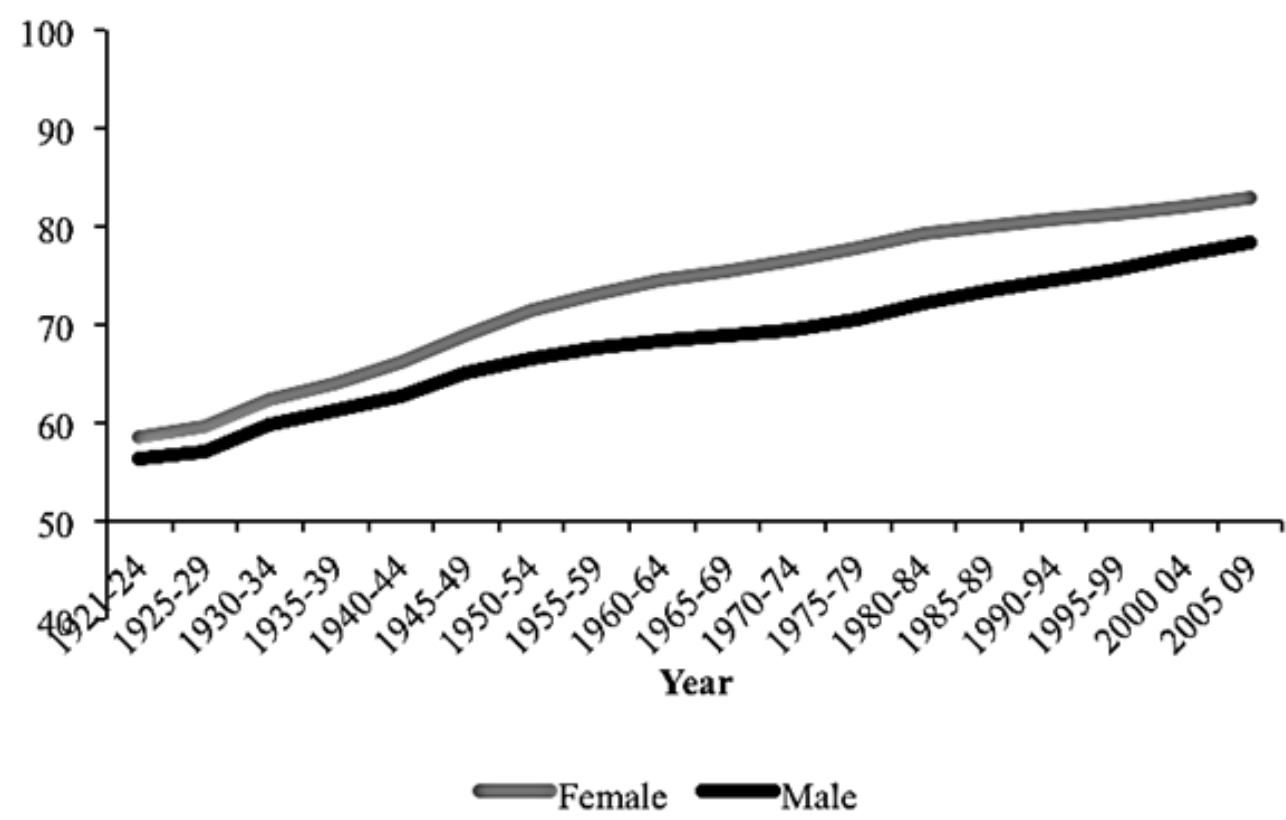

Figure 1. Life expectancy at birth by sex, Canada 1921-2009.

Source: Human Mortality Database.

(Statistics Canada 2002), health-adjusted life expectancy (Loukine et al. 2002; Manuel et al. 2002; Mathers et al. 2002; Wolfson 1996), or handicap-free and net handicap-free life expectancy (Carrière and Légaré 2000).

Canadian studies that have examined changes over time have found that gains in life expectancy have been more or less equally distributed between years lived with and without disability or dependency (Martel and Bélanger 2006; Roberge et al. 1999; Wilkins and Adams 1992 ). For example, Martel and Bélanger (2006) measured disability as dependence and found that at age 15, increases in life expectancy from 1986-1996 were largely due to increases in dependence-free years, suggesting a "compression of morbidity." For men, 1.2 of the 1.8 years' gain in life expectancy were in dependence-free years, and for women, 0.8 year of the 1 year gained was dependence-free (Martel and Bélanger 2006). Roberge and colleagues examined trends using data from 1986, 1991, and 1994 and found that disability-free life expectancy at age 15 increased over this period for both men and women (Roberge et al. 1999). They found that for men, disability-free life expectancy at age 15 increased from 53.8 years in 1986 to 54.7 years in 1991, and to 56.1 years in 1994. For women, disability-free life expectancy also increased, but at a slower rate-from 56.3 years in 1986 to 56.7 years in 1991, and to 57.3 years in 1994 (Roberge et al. 1999). No existing studies have examined trends in Canada beyond the mid-1990s.

Many studies that analyze trends in healthy life expectancy in developed countries have findings that support the theory that there has been a compression of morbidity over the last several decades (see Crimmins 2004 for a review). For example, healthy life expectancy increased for men and women in Austria (1978-1998; Doblhammer and Kytir 2001), in the United Kingdom in the 1990s (Jagger et al. 2007), and in the United States (Crimmins 2004) and France (Cambois et al. 2001). However, some evidence from other developed countries suggests that morbidity may be expanding. Examples are Australia and Japan in the 1990s (Robine and Michel 2004). Similarly, in the Netherlands from 1983-1990, gains in life expectancy were mostly concentrated in disabled years (Van De Water et al. 1996). In Japan, there was a period of morbidity compression between 1986 and 1995, and then an expansion between 1995 and 2005 (Yong and Saito 2009). 
Mandich and Margolis: Changes in disability-free life expectancy in Canada between 1994 and 2007

\section{Research questions and hypotheses}

In this paper, we examine two research questions. First, as life expectancy has increased for Canadians, did the prevalence of disability change among men and women in Canada from 1994 to 2007? Second, are the increases in life expectancy from 1994 to 2007 characterized by increases or decreases in disability-free life expectancy?

Given the existing research on disability-free life expectancy (DFLE) in Canada and other developed countries, we posit two sets of hypotheses.

- Hypothesis 1a: DFLE continues to increase in Canada, as found by Roberge et al. (1999) for the years 1986, 1991, and 1994, and Martel and Bélanger for the years 1986 and 1996 (2006).

- Hypothesis 1b: DFLE gains are minimal over the period of analysis.

- Hypothesis 2a: There will be no difference between the levels of DFLE estimated for men and women.

- Hypothesis 2b: Gains for men will be greater than gains for women, as found by Roberge et al. (1999).

\section{Method}

We estimate DFLE using the Sullivan method. Expected years healthy and disabled are calculated by applying age- and sex-specific cross-sectional prevalence rates of disability to the person-years lived in different age categories, derived from period life tables (Jagger et al. 2006; Sullivan 1971). The number of remaining years living disability-free at a given age and the number of remaining years lived disabled sum to the number of remaining years. Our estimates cover the Canadian adult population aged 20 and older. The main benefits of the Sullivan method are that it requires only cross-sectional data and that it can be used for monitoring trends over time if panel data are not available. In this paper, we examine changes in disability-free life expectancy from 1994 to 2007.We chose to examine these years because there is comparable data on disability, and we wanted to update the trends to as close to present years as possible.

\section{Data}

The Sullivan method requires two types of data-period life tables and age-specific prevalence of disability from a national survey (Jagger et al. 2006). Life tables were obtained from the Human Mortality Database. We use abridged life tables by 5 -year age intervals for men and women in Canada for 1994 and 2007. These life tables provide estimates of the person-years lived in each age interval $\left(\mathrm{n}_{\mathrm{n}}\right)$. Disability prevalence measures come from two nationally representative data sets that examine the health of the Canadian population. Data for the prevalence of disability in 1994 were obtained from the 1994-1995 National Population Health Survey (NPHS). Disability prevalence in 2007 comes from the 2007-2008 Canadian Community Health Survey (CCHS).

The 1994-1995 NPHS targets all household residents in all provinces, excluding Indian Reserves, Canadian Forces Bases, and some remote areas in Ontario and Quebec. It has a sample size of 19,600 households, and information about all household members is obtained from a knowledgeable household member (Statistics Canada 1996). We use the public-use micro-data file and weight the data to be representative of the Canadian population 20 years and older living in a private household in one 
of the ten provinces. Excluded are those living in the territories, on an Indian Reserve, on a Canadian Forces Base, in an institution, and in certain remote regions of Ontario and Quebec.

The 2007-2008 CCHS has a target population of all Canadians aged 12 and older living in private dwellings in the ten provinces and territories, excluding people living on Indian Reserves/ Crown lands, those living in institutions, full-time members of the Canadian Forces, and residents of certain remote regions (Statistics Canada 2009). In order to make the data from the two surveys comparable, we exclude from our analytic sample respondents in the Northwest Territories, Nunavut, and the Yukon. Similar to the NPHS, we also use the public-use micro-data file, and weight the data to be representative of the Canadian population 20 years and older living in a private household in one of the ten provinces, excluding the aforementioned regions.

Consistent with other research, we measure disability as needing help performing everyday activities, capturing the consequences that disability has on people's everyday lives (Carrière and Légaré 2000; Crimmins et al. 1989; Crimmins and Saito 2001). Disability is most often measured from a series of questions regarding a person's ability to function in their environment (Carrière and Légaré 2000; Crimmins and Saito 2001). In each survey, respondents were asked whether they needed help performing a set of daily tasks and activities. In the 1994-95 NPHS, respondents were asked, "Because of any condition or health problem, do you need the help of another person in: 1) preparing meals; 2) shopping for groceries or other necessities; 3) doing normal everyday housework; 4) personal care such as washing, dressing, or eating; or 5) moving about inside the house?" In the 2007-2008 CCHS, respondents were asked, "Because of any physical condition or mental condition or health problem, do you need the help of another person: 1) preparing meals; 2) getting to appointments or running errands such as shopping for groceries; 3) doing everyday housework; 4) personal care such as washing, dressing, eating, or taking medication; or 5) moving about inside the home?"2

In both surveys, three of the five tasks are described with identical wording: preparing meals, personal care, and moving about inside the home. The fourth is very similar-doing normal everyday housework and doing housework. The fifth task is "shopping for groceries/necessities" in the NPHS and "getting to appointments/ running errands" in the CCHS. These represent similar activities, because both require the respondent to leave the house to attend somewhere or pick up items. We conducted our analysis with and without this task, to test whether including the question with the difference in wording affects the results, and we found comparable results. The results shown include this task, and the results excluding the fifth task are shown in Appendix Table A1.

We code disability in two ways - as a robustness check and to compare our results to previous studies. First, we define disability as reporting needing help with at least one of the five everyday tasks. Second, we define disability as needing help with at least two of the five tasks. We estimate disability-free life expectancy for Canadian men and women separately, for ages 20 and older.

2. The wording of the question preamble differed slightly between the two surveys. The 1994-1995 NPHS stated: The next few questions deal with any health limitations which affect daily activities. In these questions, long-term conditions refer to conditions that have lasted or are expected to last 6 months or more. The next question asks about help received. This may not apply to you, but we need to ask the same questions of everyone. Because of any condition or health problem, do you need the help of another person in: [tasks listed]. "The 2007-2008 CCHS preamble stated: "The next few questions deal with any current limitations in your daily activities caused by a long-term health condition or problem. In these questions, a 'long-term condition' refers to a condition that is expected to last or has already lasted 6 months or more. The next few questions may not apply to you, but we need to ask the same questions of everyone. Because of any physical condition or mental condition or health problem do you need the help of another person [tasks listed]." 
Mandich and Margolis: Changes in disability-free life expectancy in Canada between 1994 and 2007

\section{Results}

Figure 1 plots life expectancy at birth for Canadian women and men from 1921 to 2009. The massive improvement in mortality over the 20th century was due to improvements in public health, improved nutrition, improved medical treatments, and the development of antibiotics and vaccines (Cutler et al. 2006). The more recent improvements in mortality from 1979 to 2004 are due to mortality decline at older ages, especially for deaths due to circulatory diseases and external causes such as accidents, suicides and homicides (Statistics Canada 2008). In Table 1, we zoom in on the increase in life expectancy for the period of our analysis (1994-2007). Improvements in mortality continued throughout this period, during which life expectancy increased 2.05 years for women (from 80.89 to 82.94 ) and 3.48 years for men (from 74.87 to 78.35 ).

Table 1. Life expectancy at birth by sex, Canada 1994-2007.

\begin{tabular}{lcc}
\hline & Women & Men \\
\hline 1994 & 80.89 & 74.87 \\
1995 & 80.98 & 75.01 \\
1996 & 81.11 & 75.39 \\
1997 & 81.22 & 75.67 \\
1998 & 81.39 & 75.93 \\
1999 & 81.60 & 76.15 \\
2000 & 81.81 & 76.63 \\
2001 & 81.99 & 76.91 \\
2002 & 82.01 & 77.14 \\
2003 & 82.22 & 77.30 \\
2004 & 82.45 & 77.68 \\
2005 & 82.54 & 77.84 \\
2006 & 82.93 & 78.30 \\
2007 & 82.94 & 78.35 \\
\hline
\end{tabular}

Source: Human Mortality Database.

Next, we turn to the prevalence of disability by age and sex for 1994 and 2007. The top part of Table 2 measures disability as requiring help performing at least one daily task and the bottom part measures disability as requiring help with at least two tasks. Overall, from 1994 to 2007, the prevalence of disability increased for both men and women and across the two measures. Among men, disability increased slightly among younger men (aged 20-49) and increased more among older men (aged 50+). At the oldest ages $(80+)$, we cannot detect any significant changes.

From 1994 to 2007, the prevalence of disability also increased among women. For younger women, there were small increases in disability, measured as difficulty with either one or two tasks. However, the increases were much greater among older women. For example, when measured as difficulty with one task, the prevalence of disability increased from 6.7 to 10.4 per cent among women aged 50-54, from 8.1 to 13.8 per cent among women aged 60-64, and from 17.2 to 20.4 per cent among women aged 70-74. When measured as difficulty with two or more tasks, the increases in disability for this period are focused mostly at ages 55 and above. 
Table 2. Prevalence of disability by age and sex for Canada in 1994 and 2007.

\begin{tabular}{|c|c|c|c|c|}
\hline \multirow[b]{3}{*}{ Age } & \multicolumn{4}{|c|}{ Proportion disabled (difficulty with at least 1 of 5 tasks) ${ }^{b}$} \\
\hline & \multicolumn{2}{|c|}{ Males } & \multicolumn{2}{|c|}{ Females } \\
\hline & $\begin{array}{c}1994 \\
(\mathrm{~N}=28,715)\end{array}$ & $\begin{array}{c}2007 \\
(\mathrm{~N}=50,883)\end{array}$ & $\begin{array}{c}1994 \\
(\mathrm{~N}=29,724)\end{array}$ & $\begin{array}{c}2007 \\
(\mathrm{~N}=62,840)\end{array}$ \\
\hline $20-24$ & $0.97(0.54,1.40)^{\mathrm{c}}$ & $2.58(2.03,3.14)$ & $1.34(0.84,1.85)$ & $3.25(2.67,3.84)$ \\
\hline $25-29$ & $1.08(0.60,1.55)$ & $2.89(2.34,3.43)$ & $2.60(1.90,3.30)$ & $3.74(3.19,4.29)$ \\
\hline $30-34$ & $1.23(0.79,1.68)$ & $2.47(2.00,2.93)$ & $3.35(2.68,4.03)$ & $5.12(4.51,5.72)$ \\
\hline $35-39$ & $1.34(0.89,1.79)$ & $3.33(2.80,3.85)$ & $3.74(3.04,4.44)$ & $5.89(5.24,6.53)$ \\
\hline $40-44$ & $2.48(1.85,3.11)$ & $3.98(3.42,4.53)$ & $4.59(3.76,5.42)$ & $7.56(6.83,8.28)$ \\
\hline $45-49$ & $2.03(1.41,2.64)$ & $3.66(3.11,4.20)$ & $5.64(4.64,6.64)$ & $9.00(8.20,9.79)$ \\
\hline $50-54$ & $2.30(1.53,3.07)$ & $7.05(6.34,7.76)$ & $6.71(5.37,8.04)$ & $10.37(9.61,11.14)$ \\
\hline $55-59$ & $2.70(1.74,3.66)$ & $7.31(6.60,8.02)$ & $7.19(5.68,8.71)$ & $11.68(10.89,12.48)$ \\
\hline $60-64$ & $5.63(4.17,7.10)$ & $6.43(5.73,7.13)$ & $8.05(6.37,9.74)$ & $13.80(12.91,14.69)$ \\
\hline $65-69$ & $6.21(4.62,7.81)$ & $7.45(6.62,8.28)$ & $10.83(8.81,12.85)$ & $14.57(13.56,15.58)$ \\
\hline $70-74$ & $9.93(7.72,12.15)$ & $12.77(11.62,13.93)$ & $17.17(14.64,19.69)$ & $20.40(19.17,21.63)$ \\
\hline $75-79$ & $12.88(9.67,16.09)$ & $14.83(13.47,16.19)$ & $24.92(21.39,28.45)$ & $29.50(28.05,30.94)$ \\
\hline \multirow[t]{3}{*}{$\underline{80+}$} & $32.34(27.62,37.05)$ & $34.79(33.00,36.58)$ & $45.92(41.88,49.96)$ & $50.25(48.89,51.61)$ \\
\hline & \multicolumn{4}{|c|}{ Proportion disabled (difficulty with at least 2 of 5 tasks) ${ }^{b}$} \\
\hline & \multicolumn{2}{|c|}{ Males } & \multicolumn{2}{|c|}{ Females } \\
\hline Age & 1994 & 2007 & 1994 & 2007 \\
\hline $20-24$ & $0.51(0.20,0.82)$ & $1.49(1.07,1.91)$ & $0.82(0.42,1.22)$ & $1.55(1.14,1.96)$ \\
\hline $25-29$ & $0.57(0.22,0.92)$ & $1.66(1.25,2.07)$ & $1.83(1.24,2.42)$ & $1.90(1.51,2.29)$ \\
\hline $30-34$ & $0.75(0.40,1.10)$ & $1.07(0.76,1.38)$ & $1.92(1.41,2.43)$ & $2.94(2.47,3.41)$ \\
\hline $35-39$ & $0.60(0.30,0.90)$ & $2.23(1.80,2.66)$ & $2.24(1.69,2.79)$ & $3.58(3.07,4.09)$ \\
\hline $40-44$ & $1.64(1.12,2.16)$ & $2.61(2.16,3.06)$ & $3.12(2.43,3.81)$ & $3.94(3.41,4.47)$ \\
\hline $45-49$ & $1.29(0.80,1.78)$ & $2.09(1.67,2.51)$ & $3.95(3.10,4.80)$ & $4.88(4.28,5.48)$ \\
\hline $50-54$ & $1.33(0.74,1.92)$ & $3.84(3.31,4.37)$ & $4.66(3.53,5.79)$ & $5.28(4.72,5.84)$ \\
\hline $55-59$ & $1.24(0.58,1.90)$ & $4.70(4.12,5.28)$ & $3.32(2.27,4.37)$ & $6.16(5.57,6.75)$ \\
\hline $60-64$ & $2.86(1.80,3.92)$ & $3.73(3.19,4.27)$ & $3.36(2.25,4.47)$ & $7.34(6.67,8.01)$ \\
\hline $65-69$ & $4.18(2.86,5.50)$ & $4.45(3.80,5.10)$ & $6.29(4.71,7.87)$ & $8.26(7.47,9.05)$ \\
\hline $70-74$ & $6.00(4.24,7.76)$ & $8.37(7.41,9.33)$ & $9.16(7.23,11.09)$ & $9.74(8.83,10.65)$ \\
\hline $75-79$ & $6.44(4.09,8.79)$ & $8.34(7.28,9.40)$ & $13.94(11.11,16.77)$ & $15.97(14.81,17.13)$ \\
\hline $80+$ & $23.61(19.33,27.89)$ & $21.60(20.05,23.15)$ & $28.23(24.58,31.88)$ & $31.67(30.41,32.93)$ \\
\hline
\end{tabular}

Next, we turn to the calculations of disability-free life expectancy, to examine whether the additional years of life are healthy or disabled. First, we examine the results for men in Table 3. For Canadian men, as life expectancy has increased, disability-free life expectancy has also increased. At all ages, men in 2007 can expect to live longer than in 1994, and they have more healthy years to live. For example, a 50-year-old in 1994 could expect to live 27.9 more years, 25.4 of them healthy (measured as difficulty with one task). In 2007, a 50-year old could expect to live 30.7 more years, 26.8 of them healthy years. Similarly, a 75-year-old in 1994 could expect to live 9.6 more years, 7.3 of them without disability, and in 2007 these numbers increased to 11.2 years of life remaining, 8.2 of them healthy. 
Mandich and Margolis: Changes in disability-free life expectancy in Canada between 1994 and 2007

Table 3. Life expectancy $\left(\mathrm{e}_{\mathrm{x}}\right)$ and disability-free life expectancy (DFLE) for Canadian men in 1994 and 2007.

\begin{tabular}{|c|c|c|c|c|c|c|c|c|}
\hline \multirow{3}{*}{ Age } & \multicolumn{8}{|c|}{ Disabled defined as difficulty with at least 1 of 5 tasks $^{\mathrm{a}}$} \\
\hline & $e_{x}$ & DFLE & $\begin{array}{c}\text { Disabled } \\
\text { years } \\
\left(\mathrm{e}_{\mathrm{x}}-\mathrm{DFLE}\right)\end{array}$ & $\begin{array}{c}\text { DFLE/LE } \\
(\%)\end{array}$ & $e_{x}$ & DFLE & $\begin{array}{c}\text { Disabled } \\
\text { years } \\
\left(\mathrm{e}_{\mathrm{x}}-\mathrm{DFLE}\right)\end{array}$ & $\begin{array}{c}\text { DFLE/LE } \\
(\%)\end{array}$ \\
\hline & \multicolumn{4}{|c|}{1994} & \multicolumn{4}{|c|}{2007} \\
\hline $20-24$ & 55.88 & 53.03 & 2.85 & 94.91 & 59.12 & 54.36 & 4.76 & 91.93 \\
\hline $25-29$ & 51.15 & 48.35 & 2.80 & 94.51 & 54.36 & 49.70 & 4.66 & 91.43 \\
\hline $30-34$ & 46.42 & 43.65 & 2.77 & 94.03 & 49.57 & 45.04 & 4.53 & 90.86 \\
\hline $35-39$ & 41.71 & 38.98 & 2.73 & 93.46 & 44.77 & 40.34 & 4.43 & 90.11 \\
\hline $40-44$ & 37.04 & 34.36 & 2.68 & 92.76 & 40.02 & 35.73 & 4.29 & 89.28 \\
\hline $45-49$ & 32.44 & 29.85 & 2.59 & 92.02 & 35.32 & 31.20 & 4.12 & 88.33 \\
\hline $50-54$ & 27.92 & 25.39 & 2.53 & 90.94 & 30.75 & 26.75 & 4.00 & 87.01 \\
\hline $55-59$ & 23.58 & 21.10 & 2.48 & 89.49 & 26.35 & 22.62 & 3.73 & 85.87 \\
\hline $60-64$ & 19.51 & 17.06 & 2.45 & 87.44 & 22.14 & 18.66 & 3.48 & 84.31 \\
\hline $65-69$ & 15.82 & 13.47 & 2.35 & 85.16 & 18.17 & 14.85 & 3.32 & 81.69 \\
\hline $70-74$ & 12.50 & 10.19 & 2.31 & 81.49 & 14.52 & 11.30 & 3.22 & 77.77 \\
\hline $75-79$ & 9.59 & 7.33 & 2.26 & 76.51 & 11.23 & 8.23 & 3.00 & 73.25 \\
\hline $80+$ & 7.11 & 4.81 & 2.30 & 67.66 & 8.39 & 5.47 & 2.92 & 65.41 \\
\hline \multirow{3}{*}{ Age } & \multicolumn{8}{|c|}{ Disabled defined as difficulty with at least 2 of 5 tasks $^{\mathrm{a}}$} \\
\hline & $e_{x}$ & DFLE & $\begin{array}{c}\text { Disabled } \\
\text { years } \\
\left(\mathrm{e}_{\mathrm{x}}-\mathrm{DFLE}\right)\end{array}$ & $\begin{array}{c}\text { DFLE/LE } \\
(\%)\end{array}$ & $e_{x}$ & DFLE & $\begin{array}{c}\text { Disabled } \\
\text { years } \\
\left(\mathrm{e}_{\mathrm{x}}-\mathrm{DFLE}\right)\end{array}$ & $\begin{array}{c}\text { DFLE/LE } \\
(\%)\end{array}$ \\
\hline & \multicolumn{4}{|c|}{1994} & \multicolumn{4}{|c|}{2007} \\
\hline$\overline{20-24}$ & 55.88 & 54.10 & 1.78 & 96.82 & 59.12 & 56.24 & 2.88 & 95.12 \\
\hline $25-29$ & 51.15 & 49.40 & 1.75 & 96.56 & 54.36 & 51.54 & 2.82 & 94.81 \\
\hline $30-34$ & 46.42 & 44.68 & 1.74 & 96.25 & 49.57 & 46.82 & 2.75 & 94.45 \\
\hline $35-39$ & 41.71 & 39.99 & 1.72 & 95.89 & 44.77 & 42.06 & 2.71 & 93.95 \\
\hline $40-44$ & 37.04 & 35.34 & 1.70 & 95.42 & 40.02 & 37.40 & 2.62 & 93.47 \\
\hline $45-49$ & 32.44 & 30.81 & 1.63 & 94.96 & 35.32 & 32.82 & 2.50 & 92.92 \\
\hline $50-54$ & 27.92 & 26.32 & 1.60 & 94.28 & 30.75 & 28.32 & 2.43 & 92.10 \\
\hline $55-59$ & 23.58 & 22.01 & 1.57 & 93.34 & 26.35 & 24.06 & 2.29 & 91.32 \\
\hline $60-64$ & 19.51 & 17.94 & 1.57 & 91.91 & 22.14 & 20.01 & 2.13 & 90.40 \\
\hline $65-69$ & 15.82 & 14.27 & 1.55 & 90.19 & 18.17 & 16.13 & 2.04 & 88.75 \\
\hline $70-74$ & 12.50 & 10.98 & 1.52 & 87.79 & 14.52 & 12.53 & 1.99 & 86.29 \\
\hline $75-79$ & 9.59 & 8.07 & 1.52 & 84.20 & 11.23 & 9.41 & 1.82 & 93.74 \\
\hline $80+$ & 7.11 & 5.43 & 1.68 & 76.39 & 8.39 & 6.58 & 1.81 & 78.40 \\
\hline
\end{tabular}

a The five tasks are: preparing meals, doing normal everyday housework, personal care, moving about inside the house, shopping for groceries/necessities or getting to an appointment/running errands.

However, in addition to more healthy years, Canadian men are also living longer in a disabled state. Across the two measurements for disability, there is an increased period of disabled years. We can examine the relative increases of healthy and disabled years with the last column, which shows the proportion of life remaining in a healthy state, calculated as disability-free years divided by life expectancy (DFLE/LE). Overall, years spent with disability are increasing faster than healthy years, as shown by the lower percentages of remaining life spent in a healthy state in 2007 relative to 1994 . For example, men aged 50 in 1994 could expect to live 27.9 more years, and 30.7 more years in 2007. In 1994, 90.9 per cent of these remaining years would be spent disability-free, but in 2007, only 87 per cent are disability-free, measuring disability as difficulty with one or more tasks. The same pattern 
is clear when we measure disability as difficulty with two or more tasks. The one difference between the two measures is for the oldest men (ages 75+). When measuring disability as difficulty with at least one task, it shows that the proportion of healthy years remaining decreased slightly over the period (from 76.5 to 73.3 per cent for 75-79-year-olds, and from 67.7 to 65.4 per cent for those 80 and older). However, there is an increase in the proportion of life disability-free when measuring it more stringently, meaning that time spent disabled because of multiple limitations is not increasing as quickly as time spent disabled because of only one limitation among the oldest men.

Table 4 presents the results for disability-free life expectancy for women. Similar to the pattern for men, life expectancy for women increased between 1994 and 2007. However, disability-free life expect-

Table 4. Life expectancy $\left(e_{x}\right)$ and disability-free life expectancy (DFLE) for Canadian women in 1994 and 2007.

\begin{tabular}{|c|c|c|c|c|c|c|c|c|}
\hline \multirow{3}{*}{ Age } & \multicolumn{8}{|c|}{ Disabled defined as difficulty with at least 1 of 5 tasks $^{\mathrm{a}}$} \\
\hline & $\mathrm{e}_{\mathrm{x}}$ & DFLE & $\begin{array}{c}\text { Disabled } \\
\text { years } \\
\left(\mathrm{e}_{\mathrm{x}}-\mathrm{DFLE}\right)\end{array}$ & $\begin{array}{c}\text { DFLE/LE } \\
(\%)\end{array}$ & $e_{x}$ & DFLE & $\begin{array}{c}\text { Disabled } \\
\text { years } \\
\left(\mathrm{e}_{\mathrm{x}}-\mathrm{DFLE}\right)\end{array}$ & $\begin{array}{c}\text { DFLE/LE } \\
(\%)\end{array}$ \\
\hline & \multicolumn{4}{|c|}{1994} & \multicolumn{4}{|c|}{2007} \\
\hline$\overline{20-24}$ & 61.65 & 54.83 & 6.82 & 88.94 & 63.57 & 53.99 & 9.58 & 84.93 \\
\hline $25-29$ & 56.75 & 49.99 & 6.76 & 88.09 & 58.66 & 49.23 & 9.43 & 83.93 \\
\hline $30-34$ & 51.85 & 45.21 & 6.64 & 87.19 & 53.75 & 44.50 & 9.25 & 82.78 \\
\hline $35-39$ & 46.98 & 40.48 & 6.50 & 86.18 & 48.86 & 39.84 & 9.02 & 81.54 \\
\hline $40-44$ & 42.15 & 35.82 & 6.33 & 84.98 & 44.00 & 35.25 & 8.75 & 80.11 \\
\hline $45-49$ & 37.39 & 31.25 & 6.14 & 83.58 & 39.21 & 30.79 & 8.42 & 78.53 \\
\hline $50-54$ & 32.74 & 26.82 & 5.92 & 81.93 & 34.53 & 26.49 & 8.04 & 76.71 \\
\hline 55-59 & 28.23 & 22.55 & 5.68 & 79.90 & 29.95 & 22.33 & 7.62 & 74.54 \\
\hline $60-64$ & 23.91 & 18.45 & 5.46 & 77.16 & 25.52 & 18.32 & 7.20 & 71.82 \\
\hline $65-69$ & 19.78 & 14.51 & 5.27 & 73.34 & 21.25 & 14.53 & 6.72 & 68.37 \\
\hline $70-74$ & 15.92 & 10.85 & 5.07 & 68.19 & 17.24 & 10.91 & 6.33 & 63.28 \\
\hline $75-79$ & 12.38 & 7.66 & 4.72 & 61.93 & 13.51 & 7.70 & 5.81 & 56.97 \\
\hline$\underline{80+}$ & 9.23 & 4.99 & 4.24 & 54.08 & 10.13 & 5.04 & 5.09 & 49.75 \\
\hline \multirow{3}{*}{ Age } & \multicolumn{8}{|c|}{ Disabled defined as difficulty with at least 2 of 5 tasks $^{\mathrm{a}}$} \\
\hline & $e_{x}$ & DFLE & $\begin{array}{c}\text { Disabled } \\
\text { years } \\
\left(\mathrm{e}_{\mathrm{x}}-\mathrm{DFLE}\right)\end{array}$ & $\begin{array}{c}\text { DFLE/LE } \\
(\%)\end{array}$ & $e_{x}$ & DFLE & $\begin{array}{c}\text { Disabled } \\
\text { years } \\
\left(\mathrm{e}_{\mathrm{x}}-\mathrm{DFLE}\right)\end{array}$ & $\begin{array}{c}\text { DFLE/LE } \\
(\%)\end{array}$ \\
\hline & \multicolumn{4}{|c|}{1994} & \multicolumn{4}{|c|}{2007} \\
\hline$\overline{20-24}$ & 61.65 & 57.64 & 4.01 & 93.50 & 63.57 & 58.14 & 5.43 & 91.45 \\
\hline $25-29$ & 56.75 & 52.77 & 3.98 & 92.99 & 58.66 & 53.30 & 5.36 & 90.85 \\
\hline $30-34$ & 51.85 & 47.96 & 3.89 & 92.50 & 53.75 & 48.47 & 5.28 & 90.18 \\
\hline $35-39$ & 46.98 & 43.17 & 3.81 & 91.90 & 48.86 & 43.72 & 5.14 & 89.47 \\
\hline $40-44$ & 42.15 & 38.44 & 3.71 & 91.20 & 44.00 & 39.02 & 4.98 & 88.68 \\
\hline $45-49$ & 37.39 & 33.82 & 3.57 & 90.44 & 39.21 & 34.40 & 4.81 & 87.74 \\
\hline $50-54$ & 32.74 & 29.33 & 3.41 & 89.58 & 34.53 & 29.92 & 4.61 & 86.66 \\
\hline $55-59$ & 28.23 & 24.99 & 3.24 & 88.55 & 29.95 & 25.55 & 4.40 & 85.31 \\
\hline $60-64$ & 23.91 & 20.76 & 3.15 & 86.83 & 25.52 & 21.34 & 4.18 & 83.52 \\
\hline $65-69$ & 19.78 & 16.67 & 3.11 & 84.29 & 21.25 & 17.31 & 3.94 & 81.45 \\
\hline $70-74$ & 15.92 & 12.93 & 2.99 & 81.22 & 17.24 & 13.51 & 3.73 & 78.39 \\
\hline $75-79$ & 12.38 & 9.54 & 2.84 & 77.11 & 13.51 & 9.97 & 3.54 & 73.79 \\
\hline $80+$ & 9.23 & 6.63 & 2.60 & 71.77 & 10.13 & 6.92 & 3.21 & 68.33 \\
\hline
\end{tabular}

a The five tasks are: preparing meals, doing normal everyday housework, personal care, moving about inside the house, shopping for groceries/necessities or getting to an appointment/running errands. 
Mandich and Margolis: Changes in disability-free life expectancy in Canada between 1994 and 2007

ancy has stayed constant for women, rather than increasing as it did for men. For example, women's life expectancy at age 50 increased from 32.7 in 1994 to 34.5 in 2007. However, disability-free years at age 50 remained about the same (26.8 years in 1994 and 26.5 years in 2007). Similarly, at age 75, women could expect to live 12.4 years in 1994, and this increased to 13.5 years. However, the remaining healthy years remained constant at 7.7 years. The trend is similar for both measures of disability shown.

The increase in life expectancy for women is mostly due to increases in disabled years rather than healthy years, leading to a smaller percentage of remaining years lived disability-free. This is evident in the last column in Table 4, which shows the proportion of life remaining in a healthy state as disabilityfree years divided by life expectancy (DFLE/LE). At all ages and across both measures of disability, Canadian women are living smaller proportions of their remaining lives in a healthy state. For example, in 1994 women aged 50 could expect to live 32.7 more years, with 26.8 healthy and 5.9 disabled, or 81.9 per cent of remaining years being healthy years. Although they have more remaining years in 2007 (34.5 years), 26.5 are healthy and 8.0 are disabled, so that only 77 per cent of remaining life is disability-free. This is also apparent at older ages. In 1994, a woman aged 75 could expect to live 12.4 more years, 7.7 of them healthy and 4.7 disabled (61.9 per cent of remaining years healthy). However, in 2007 , although the woman could expect to live more than a year longer (13.5 years), and healthy years stayed the same, but disabled years increased to 5.8 ( 57 per cent healthy). In sum, the increases in life expectancy for women were mostly characterized by increases in disabled rather than healthy years.

\section{Sensitivity analysis}

We conducted four additional analyses to test the robustness of the results and potential explanations for the patterns we found. First, the results are robust to three different definitions of disability. In the paper, we present results characterizing disability as either at least one or at least two of five tasks. In additional analysis, we tested whether the slight difference in question wording regarding the fifth task affected the results. We excluded this question and defined disability as at least one of four tasks, and found very similar results. These results are available in Appendix Table A1.

Second, we estimated disability-free life expectancy by province, to test whether the results were driven by one or several of the provinces. This was not the explanation for our findings. For men, we found that all the provinces followed patterns in disability-free life expectancy similar to the national trends presented in this paper. For women, we found that most provinces, including the largest provinces (Ontario, British Columbia, and Quebec), followed the trends presented in the paper. Newfoundland and Labrador, Prince Edward Island, Manitoba, and Alberta did not follow the national trend. Each of these provinces had decreases in disability-free life expectancy for women, especially in the oldest age group. However, these provinces are relatively small in terms of population, together making up 16.3 per cent of the Canadian population. Also, because of the smaller sample sizes of these provinces with relatively small populations, the estimates of disability were less precise. Future research on disability in Canada should examine the contributing factors to higher levels of disability among women in these provinces.

Third, we examined to what extent the exclusion of the institutionalized population, which was not part of the surveys we analyzed, affected the results. If the proportion of the population that was institutionalized increased dramatically over the study period, this could be a potential explanation for our findings, because this subpopulation has higher levels of disability than the populations surveyed in the CCHS and NPHS. The percentage of Canadians living in institutions increased slightly, but not dramatically, over this period. According to the 1996 and 2006 censuses, the institutionalized population increased from 1.56 per cent to 1.69 per cent over this period (Statistics Canada 2011). Therefore, excluding institutionalized Canadians is not likely to affect the results. 
Last, we tested whether the increase in the proportion of immigrants and their differential health was driving the results. Using the NPHS and CCHS, we estimated the prevalence of disability by nativity and sex for the two periods. The proportion of the population that was foreign-born increased from 17.1 to 22.1 per cent for men, and from 17.6 to 22.5 per cent for women. Despite a large literature on the "healthy immigrant effect" that documents superior outcomes for immigrants (Elo et al. 2011; Huang et al. 2011; Palloni and Morenoff 2001; Wu and Schimmele 2005), and other research documenting that immigrants have lower levels of disability compared to the native-born (Chen et al. 1996), we do not find lower rates of disability for immigrants than the native-born. Appendix Table A2 shows that in most age groups, there are no significant differences in disability by nativity. However in 2007, disability was significantly higher among men aged 50-54 and 55-59 and among women aged 60-64 and 70-74. Increased immigration and higher levels of disability in some age groups among the foreign-born may be a small factor explaining the patterns found, but this does not seem to be driving the results.

\section{Discussion}

This paper examined changes in the prevalence of disability and disability-free life expectancy for Canadian men and women in 1994 to 2007. We examined whether Canadians are living longer, healthier lives or whether they are living longer but in poor health. Using the Sullivan method, we estimated whether remaining years are disabled or disability-free. Several Canadian studies have examined trends over time, but these trends have only been examined up to the mid-1990s (Martel and Bélanger 2006; Roberge et al. 1999; Wilkins and Adams 1992). We updated the trend over time, which was last examined by Martel and Bélanger (2006) for the period 1986-1996. We found that although life expectancy increased for both men and women during this period, the gains were not mirrored by comparable increases in disability-free life expectancy.

We found different patterns in the DFLE trend for men and women. For men, we found that there were increases in both disability-free life expectancy and disabled years. Even though healthy life expectancy increased for men between 1994 and 2007, years spent with disability increased faster than healthy years. This led to an increase in the proportion of life remaining spent with disability for men in 2007 relative to 1994. This pattern of results is quite robust, given that it was found across the three measures of disability we tested. Comparing our results with other Canadian studies, we find similarities and differences. Studies which cover the mid-1980s to mid-1990s find increases in disability-free years and a decreasing or similar proportion of remaining years spent disabled (Martel and Bélanger 2006; Roberge et al. 1999). We also find that DFLE at ages 20-24 increased for men from 1994 to 2007, but disabled years increased at a faster rate than healthy years, leading to an increasing number of remaining years spent disabled. Thus, for men, we do not find clear support for either the "compression of morbidity" or "expansion of morbidity" theoretical framework. There were increases in both DFLE and remaining years disabled.

On the other hand, for women disability-free life expectancy remained fairly constant across the time period of study. The increases in life expectancy for women were mostly characterized by increases in disabled rather than healthy years. Thus, a decreasing proportion of remaining years are being spent free of disability among Canadian women. Studies done by Roberge and colleagues (1999) and Martel and Bélanger (2006) found very small increases in DFLE at age 15 for women, and a relatively constant percentage of remaining years spent disabled. Our results are more pessimistic than those of Roberge and colleagues (1999) and Martel and Bélanger (2006). The clear decrease in the propor- 
Mandich and Margolis: Changes in disability-free life expectancy in Canada between 1994 and 2007

tion of life spent disability-free for women from 1994 to 2007 supports the "expansion of morbidity" theory, which is consistent with recent trends in other low mortality countries such as Australia, the Netherlands, and Japan (Robine and Michel 2004; Van De Water et al. 1996; Yong and Saito 2009).

This study is not without limitations. First, the Sullivan method draws on cross-sectional data and relies on stationary population model assumptions to draw conclusions about disability in a hypothetical cohort. This limitation could be tested with a cohort life table and either consecutive cross-sectional or longitudinal data (Imai and Soneji 2007). However, cohort life tables and recent longitudinal data on disability for Canada are not available. We used the Sullivan method because of data limitations, and also to compare trends in disability-free life expectancy for Canada to other countries. A second limitation is that we measure disability with a dichotomous measure, and we do not model transitions among different disabled states. However, we do measure disability in three ways for this study - difficulty with one of five, two of five, and one of four tasks - and we find similar results across the three measures. Third, the wording of the preamble to the questions about disability was not identical across the two surveys. Future work can examine whether the wording differences between "Because of any condition or health problem" and "Because of any physical condition or mental condition or health problem" make any difference. Fourth, this study employs data from two time points, and because there is variability in disability prevalence from year to year, more time periods are needed to better document trends. Finally, this study uses data from two large national surveys, but it does not include the institutionalized population in Canada. Disability measures on the institutionalized population were not available. However, in our sensitivity analysis, we estimate that even if we assumed that the entire institutionalized population of Canada was disabled, this would not affect the trends shown in the paper.

Despite any limitations, this paper makes an important contribution to research on trends in morbidity and mortality in developed countries. The implications are important within the context of population aging. The recent increase in life expectancy for Canada has not been matched by large increases in disability-free life expectancy. Thus, both the percentage and the number of Canadians who require the help of another person with their daily activities is increasing, and policymakers should consider how this need will be met. In our study, we could not address whether respondents had family members or caregivers available to offer assistance with daily activities. Future research should examine not only whether people require assistance, but also whether they are getting assistance. A good framework to use is that of "net handicap-free life expectancy," created by Carrière and Légaré (2000), which factored in met and unmet need for daily activities. If people have help at home, they may be able to continue living on their own. But if they do not, then the government may face added pressure on long-term healthcare facilities. Our findings also highlight policy-relevant gender differences. We find a greater expansion of morbidity among women than men. In addition to living longer, women have higher levels of disability, will spend a greater proportion of their lives disabled, and more often live alone. Thus, policy decisions about how to provide care to disabled older Canadians are inherently gendered.

\section{References}

Bélanger, A., L. Martel, J-M. Berthelot, and R. Wilkins. 2008. Gender differences in disability-free life expectancy for selected risk factors and chronic conditions in Canada. Journal of Women \& Aging 14(1-2):61-83.

Bronnum-Hansen, H., O. Anderson, M. Kjoller, and N.K. Rasmussen. 2004. Social gradient in life expectancy and health expectancy in Denmark. Sozial-Und Praventivmedizin 49:36-41. 
Cambois, E., J.M. Robine, and, M.D. Hayward. 2001. Social inequalities in disability-free life expectancy in the French male population, 1980-1991. Demography 38(4):513-524.

Carrière, Y., and J. Légaré 2000. Unmet need for assistance with ADLs and IADLs: A measure of healthy life expectancy. Social Indicators Research 51(1):107-123.

Chen, J., R. Wilkins, and E. Ng. 1996. Health expectancy by immigrant status. Health Reports 8(3):29-37.

Crimmins, E.M. 2004. Trends in the health of the elderly. Annual Review of Public Health 25L 79-98.

Crimmins, E.M., and Y. Saito. 2001. Trends in healthy life expectancy in the United States, 1970-1990: Gender, racial, and educational differences. Social Science \& Medicine 52:1629-1641.

Crimmins, E.M., Y. Saito, and D. Ingegneri. 1989. Changes in life expectancy and disability-free life expectancy in the United States. Population and Development Review 15(2):235-267.

Cutler, D., A. Deaton, and A. Lleras-Muney. 2006. The determinants of mortality. Journal of Economic Perspectives 20(3):97-120.

Doblhammer, G., and J. Kytir. 2001. Compression or expansion of morbidity? Trends in healthy-life expectancy in the elderly Austrian population between 1978 and 1998. Social Science \& Medicine 52:385-391.

Elo, I.T., N.K. Mehta, and C. Huang. 2011. Disability among native-born and foreign-born Blacks in the United States. Demography 48:241-265.

Fries, J.F. 1980. Aging, natural death and the compression of morbidity. New England Journal of Medicine 303:130-135.

Graham, P., T. Blakely, P. Davis, A. Sporle, and N. Pearce .2004. Compression, expansion, or dynamic equilibrium? The evolution of health expectancy in New Zealand." Journal of Epidemiology and Community Health 58:659-666.

Gruenberg, E. 1977. The failures of success. Milbank Memorial Foundation Quarterly/Health and Society $55: 3-24$.

Huang, C., N.K. Mehta, I.T. Elo, S.A. Cunningham, R. Stephenson, D.F. Williamson, and K.M. Venkat Narayan. 2011. Region of birth and disability among recent U.S. Immigrants: Evidence from the 2000 Census. Population Research and Policy Review 30:399-418.

Human Mortality Database. 2013. Canada, life expectancy at birth (period, 1x5). http://www.mortality. org/hmd/CAN/STATS/E0per_1x5.txt (retrieved March 4, 2013)

Ibbott, P., D. Kerr, and R. Beaujot. 2006. Probing the future of mandatory retirement in Canada. Canadian Journal on Aging 25(2):161-178.

Imai, K., and S. Soneji. 2007. On the estimation of disability-free life expectancy: Sullivan's method and its extension. Journal of the American Statistical Association 102(480):1199-1211.

Jagger, C., B. Cox, S. Le Roy, EHEMU. 2006. Health expectancy calculation by the Sullivan Method. 3rd edn. EHEMU Technical Report September 2006.

Kramer, M. 1980. The rising epidemic of mental disorders and associated chronic diseases and disabilities. Acta Psycbiatrica Scandinavica 62:282-297.

Loukine, L., C. Waters, B.C.K. Choi, and J. Ellison. 2012. Impact of diabetes mellitus on life expectancy and health-adjusted like expectancy in Canada. Population and Health Metrics 10:7. 
Mandich and Margolis: Changes in disability-free life expectancy in Canada between 1994 and 2007

Manton, K. 1982. Changing concepts of morbidity and mortality in the elderly population. Milbank Memorial Fund Quarterly/ Health and Society 60:183-244.

Manuel, D.G., S.E. Schultz, and J.A. Kopec. 2002. Measuring the health burden of chronic disease and injury using health adjusted life expectancy and the Health Utilities Index. Journal of Epidemiology and Community Health 56(11):843-850.

Martel, L., and A. Bélanger. 2006. An analysis of the change in dependence-free life expectancy in Canada between 1986 and 1996. Report on the Demographic Situation in Canada, 1998-1999. Statistics Canada Catalogue no. 91-209-XPE.

Mathers, C.D., C.J.L. Murray, A.D. Lopez, R. Sadana, and J. Salomon. 2002. Global patterns of healthy life expectancy for older women. Journal of Women \& Aging 14(1-2):99-117.

Mayer, F., N. Ross, J. Berthelot, and, R. Wilkins 2002. Disability-free life expectancy by health region. Health Reports 13(4):49-60.

Murray, C., and A. Lopez. 1996. The Global Burden of Disease: A Comprehensive Assessment of Mortality and Disability from Diseases, Injuries and Risk. Factors in 1990 and Projected to 2020. Cambridge MA: Harvard University Press.

Musgrove, P., A. Creese, A. Preker, C. Baeza, A. Anell, and Prentice T. 2000. Health Systems: Improving Performance, World Health Report 2000. Geneva: World Health Organization.

Olshansky, S.J., M.A. Rudberg, B.A. Carnes, B.A. Cassel, and J.A. Brady. 1991. Trading off longer life for worsening health: The expansion of morbidity hypothesis. Journal of Aging and Health 3:194-216.

Palloni, A., and J.D. Morenoff. 2001. Interpreting the paradoxical in the Hispanic Paradox: Demographic and epidemiologic approaches. Annals of the New York Academy of Sciences 954:140-174.

Roberge, R., J-M. Berthelot, and K. Cranswick. 1999. Adjusting life expectancy to account for disability in a population: A comparison of three techniques. Social Indicators Research 48:217-243.

Robine, J.M., and J.P. Michel. 2004. Looking forward to a general theory on population. Journal of Gerontology: Medical Sciences 59(A):590-597.

Statistics Canada. 1996. National Population Health Survey, 1994-1995 [Canada]: General file. [machine readable data file]. Ottawa: Statistics Canada [producer(s)], Statistics Canada, Data Liberation Initiative [distributor(s)]. 04-26-1996. http://equinox2.uwo.ca/Docfiles/1994nphs/nphs1996ensp1996-1-eng.pdf (retrieved December 3, 2012).

— 2001. How healthy are Canadians? 2001 Annual Report. Health Reports 12(3):1-59.

2002. Disability-adjusted life expectancy, abridged life table, at birth and at age 65, by sex, Canada, provinces, territories, and health regions. http://www5.statcan.gc.ca/cansim/pick-choisir?1 ang=eng\&p2=33\&id=1020020 (retrieved December 3, 2012).

. 2008. Components of population growth. http://www.statcan.gc.ca/pub/91-003x/2007001/4129903-eng.htm (retrieved May 5, 2013).

. 2009. Canadian Community Health Survey, 2007/2008: Cycle 4.1. [machine readable data file]. Ottawa: Statistics Canada [producer(s)], Statistics Canada, Data Liberation Initiative [distributor(s)]. 2009-07-09. http://equinox2.uwo.ca/docfiles/cchs/c4.1/cchs_2007-2008_user_guide.pdf (retrieved December 3, 2012). 
2011. Population, Private Dwellings Occupied by Usual Residents, Private Households, Average Number of Persons per Private Household, Collective Dwellings Occupied by Usual Residents and Population in Collective Dwellings of Canada, Provinces and Territories, 1971 to 2011 Censuses. http://www12.statcan.gc.ca/census-recensement/2011/dp-pd/tbt-tt/Rp-eng.cfm?LANG=E\&APA $\mathrm{TH}=3 \& D E T A I L=0 \& D I M=0 \& F L=A \& F R E E=0 \& G C=0 \& G I D=0 \& G K=0 \& G R P=1 \& P I D=1022$ $40 \&$ PRID $=0 \&$ PTYPE $=101955 \& S=0 \&$ SHOWALL $=0 \& S U B=0 \&$ Temporal $=2011 \&$ THEME $=91 \&$ VID $=0 \&$ VNAMEE $=\&$ VNAMEF (retrieved July 25,2013 ).

Sullivan, D. 1971. A single index of mortality and morbidity. HSMHA Health Reports 86:347-354.

Van de Water, H., H. Boshuizen, R. Perenboom, C. Mathers, and J.M. Robine. 1996. Health expectancy: An indicator for change? Journal of Epidemiology and Community Health 49:330-332.

Wilkins, R., and O. Adams. 1992. Les tendances de l'espérance de vie en santé au Canada, 1951-1986. In Espérances de santé, edited by J-M. Robine, M. Blanchet, and J.E. Dowd. Collection Analyse et Prospective. Paris: Éditions INSERM.

Wolfson, M.C. 1996. Health-adjusted life expectancy. Health Reports 8(1):41-46.

Wu, Z., and C. Schimmele. 2005. The healthy migrant effect on depression: Variation over time? Canadian Studies in Population 32(2):271-295.

Yong, V., and Y. Saito. 2009. Trends in healthy life expectancy in Japan: 1986-2004. Demographic Research 20(19):467-494. 
Mandich and Margolis: Changes in disability-free life expectancy in Canada between 1994 and 2007

\section{APPENDIX}

Table A1. Disability-free life expectancy (DFLE) for Canadian men and women in 1994 and 2007, defining disability as difficulty with at least 1 of 4 tasks .

\begin{tabular}{|c|c|c|c|c|c|c|c|c|}
\hline \multirow{3}{*}{ Age } & \multicolumn{8}{|c|}{ Men } \\
\hline & $e_{x}$ & $\begin{array}{c}\% \\
\text { disabled }\end{array}$ & DFLE & $\begin{array}{c}\text { DFLE/LE } \\
(\%)\end{array}$ & $e_{x}$ & $\begin{array}{c}\% \\
\text { disabled }\end{array}$ & DFLE & $\begin{array}{c}\text { DFLE/LE } \\
(\%)\end{array}$ \\
\hline & \multicolumn{4}{|c|}{1994} & \multicolumn{4}{|c|}{2007} \\
\hline $20-24$ & 55.88 & 0.74 & 53.33 & 95.44 & 59.12 & 2.07 & 55.03 & 93.08 \\
\hline $25-29$ & 51.15 & 0.95 & 48.63 & 95.06 & 54.36 & 2.49 & 50.35 & 92.63 \\
\hline $30-34$ & 46.42 & 1.05 & 43.93 & 94.63 & 49.57 & 2.01 & 45.67 & 92.14 \\
\hline $35-39$ & 41.71 & 1.10 & 39.25 & 94.12 & 44.77 & 2.89 & 40.95 & 91.48 \\
\hline $40-44$ & 37.04 & 2.34 & 34.62 & 93.47 & 40.02 & 3.69 & 36.33 & 90.78 \\
\hline $45-49$ & 32.44 & 1.72 & 30.11 & 92.82 & 35.32 & 3.19 & 31.79 & 89.99 \\
\hline $50-54$ & 27.92 & 1.96 & 25.64 & 91.83 & 30.75 & 6.25 & 27.33 & 88.88 \\
\hline $55-59$ & 23.58 & 2.17 & 21.34 & 90.49 & 26.35 & 6.94 & 23.17 & 87.94 \\
\hline $60-64$ & 19.51 & 5.00 & 17.28 & 88.57 & 22.14 & 5.63 & 19.21 & 86.76 \\
\hline $65-69$ & 15.82 & 5.53 & 13.68 & 86.45 & 18.17 & 6.88 & 15.38 & 84.61 \\
\hline $70-74$ & 12.50 & 9.55 & 10.38 & 83.03 & 14.52 & 11.08 & 11.84 & 81.55 \\
\hline $75-79$ & 9.59 & 11.48 & 7.55 & 78.73 & 11.23 & 12.73 & 8.76 & 78.01 \\
\hline$\underline{80+}$ & 7.11 & 29.44 & 5.01 & 70.56 & 8.39 & 28.23 & 6.03 & 71.77 \\
\hline \multirow{3}{*}{ Age } & \multicolumn{8}{|c|}{ Women } \\
\hline & $e_{x}$ & $\begin{array}{c}\% \\
\text { disabled }\end{array}$ & DFLE & $\begin{array}{c}\text { DFLE/LE } \\
(\%)\end{array}$ & $e_{x}$ & $\begin{array}{c}\% \\
\text { disabled }\end{array}$ & DFLE & $\begin{array}{c}\text { DFLE/LE } \\
(\%)\end{array}$ \\
\hline & \multicolumn{4}{|c|}{1994} & \multicolumn{4}{|c|}{2007} \\
\hline$\overline{20-24}$ & 61.65 & 1.23 & 56.04 & 90.90 & 63.57 & 2.38 & 55.81 & 87.79 \\
\hline $25-29$ & 56.75 & 2.21 & 51.19 & 90.21 & 58.66 & 3.22 & 51.01 & 86.95 \\
\hline $30-34$ & 51.85 & 2.98 & 46.40 & 89.47 & 53.75 & 4.60 & 46.25 & 86.03 \\
\hline $35-39$ & 46.98 & 3.36 & 41.65 & 88.67 & 48.86 & 5.33 & 41.57 & 85.08 \\
\hline $40-44$ & 42.15 & 4.23 & 36.98 & 87.72 & 44.00 & 6.35 & 36.95 & 83.98 \\
\hline $45-49$ & 37.39 & 5.17 & 32.40 & 86.64 & 39.21 & 8.23 & 32.44 & 82.75 \\
\hline $50-54$ & 32.74 & 6.16 & 27.95 & 85.39 & 34.53 & 8.69 & 28.12 & 81.44 \\
\hline $55-59$ & 28.23 & 5.34 & 23.67 & 83.88 & 29.95 & 10.03 & 23.90 & 79.78 \\
\hline $60-64$ & 23.91 & 6.41 & 19.50 & 81.59 & 25.52 & 11.69 & 19.84 & 77.76 \\
\hline $65-69$ & 19.78 & 9.75 & 15.53 & 78.49 & 21.25 & 12.41 & 15.99 & 75.23 \\
\hline $70-74$ & 15.92 & 14.22 & 11.88 & 74.67 & 17.24 & 15.72 & 12.33 & 71.54 \\
\hline $75-79$ & 12.38 & 21.03 & 8.65 & 69.92 & 13.51 & 22.89 & 9.00 & 66.61 \\
\hline $80+$ & 9.23 & 35.49 & 5.96 & 64.51 & 10.13 & 38.98 & 6.18 & 61.02 \\
\hline
\end{tabular}

a The four tasks are: preparing meals, doing normal everyday housework, personal care, moving about inside the house. 
Table A2. Prevalence (\%) of disability by age and nativity: Canada 1994 and $2007^{\text {b }}$.

\begin{tabular}{|c|c|c|c|c|}
\hline \multirow{3}{*}{ Age } & \multicolumn{4}{|c|}{ Men } \\
\hline & \multicolumn{2}{|c|}{ Native-born } & \multicolumn{2}{|c|}{ Immigrants } \\
\hline & 1994 & 2007 & 1994 & 2007 \\
\hline $20-24$ & $1.10(0.63,1.57)^{\mathrm{c}}$ & $2.91(2.29,3.53)$ & 0 & $1.17(0.00,2.43)$ \\
\hline $25-29$ & $1.29(0.73,1.85)$ & $2.44(1.91,2.97)$ & 0 & $4.81(2.64,6.98)$ \\
\hline $30-34$ & $1.32(0.83,1.81)$ & $2.62(2.10,3.14)$ & $0.86(0.00,1.90)$ & $2.25(0.97,3.53)$ \\
\hline $35-39$ & $1.52(1.00,2.04)$ & $3.39(2.80,3.98)$ & $0.65(0.00,1.47)$ & $3.27(1.99,4.55)$ \\
\hline $40-44$ & $2.64(1.93,3.35)$ & $4.42(3.77,5.07)$ & $1.89(0.46,3.32)$ & $3.04(1.85,4.23)$ \\
\hline $45-49$ & $2.25(1.53,2.97)$ & $3.89(3.29,4.49)$ & $1.37(0.24,2.50)$ & $2.84(1.36,4.32)$ \\
\hline $50-54$ & $2.45(1.56,3.34)$ & $5.41(4.74,6.08)$ & $1.90(0.38,3.42)$ & $11.67(9.01,14.33)$ \\
\hline $55-59$ & $2.80(1.71,3.89)$ & $6.39(5.66,7.12)$ & $2.39(0.33,4.45)$ & $9.42(7.31,11.53)$ \\
\hline $60-64$ & $6.03(4.33,7.73)$ & $7.22(6.40,8.04)$ & $4.50(1.60,7.40)$ & $4.26(2.85,5.67)$ \\
\hline $65-69$ & $6.30(4.33,8.27)$ & $7.26(6.34,8.18)$ & $6.01(2.67,9.35)$ & $7.62(5.68,9.56)$ \\
\hline $70-74$ & $10.28(7.77,12.79)$ & $11.53(10.27,12.79)$ & $8.74(4.01,13.47)$ & $15.33(12.55,18.11)$ \\
\hline $75-79$ & $14.63(11.00,18.26)$ & $15.12(13.56,16.68)$ & $3.18(0.00,7.86)$ & $14.14(11.09,17.19)$ \\
\hline $80+$ & $29.79(24.50,35.08)$ & $33.64(31.60,35.68)$ & $38.54(28.54,48.54)$ & $38.66(34.67,42.65)$ \\
\hline Total & 2.50 & 5.57 & 2.92 & 7.11 \\
\hline
\end{tabular}

\begin{tabular}{|c|c|c|c|c|}
\hline \multirow{3}{*}{ Age } & \multicolumn{4}{|c|}{ Women } \\
\hline & \multicolumn{2}{|c|}{ Native-born } & \multicolumn{2}{|c|}{ Immigrants } \\
\hline & 1994 & 2007 & 1994 & 2007 \\
\hline $20-24$ & $1.27(0.75,1.79)$ & $2.91(2.32,3.50)$ & $2.42(0.18,4.66)$ & $5.02(2.60,7.44)$ \\
\hline $25-29$ & $2.84(2.06,3.62)$ & $3.79(3.20,4.38)$ & $1.58(0.09,3.07)$ & $3.14(1.62,4.66)$ \\
\hline $30-34$ & $3.71(2.95,4.47)$ & $5.15(4.49,5.81)$ & $1.85(0.44,3.26)$ & $5.15(3.50,6.80)$ \\
\hline $35-39$ & $3.73(2.97,4.49)$ & $6.50(5.75,7.25)$ & $3.79(1.89,5.69)$ & $4.43(3.03,5.83)$ \\
\hline $40-44$ & $4.47(3.57,5.37)$ & $7.65(6.85,8.45)$ & $4.99(2.86,7.12)$ & $7.51(5.62,9.40)$ \\
\hline $45-49$ & $5.80(4.67,6.93)$ & $8.46(7.63,9.29)$ & $5.17(2.99,7.35)$ & $10.44(8.06,12.82)$ \\
\hline $50-54$ & $6.64(5.16,8.12)$ & $10.06(9.24,10.88)$ & $6.91(3.79,10.03)$ & $11.04(8.72,13.36)$ \\
\hline $55-59$ & $7.44(5.73,9.15)$ & $11.05(10.20,11.90)$ & $6.48(3.20,9.76)$ & $13.62(11.44,15.80)$ \\
\hline $60-64$ & $7.71(5.87,9.55)$ & $12.70(11.75,13.65)$ & $9.25(5.17,13.33)$ & $16.77(14.35,19.19)$ \\
\hline $65-69$ & $9.48(7.31,11.65)$ & $13.81(12.71,14.91)$ & $14.34(9.55,19.13)$ & $16.68(14.07,19.29)$ \\
\hline $70-74$ & $16.96(14.16,19.76)$ & $18.91(17.57,20.25)$ & $17.86(12.07,23.65)$ & $24.34(21.22,27.46)$ \\
\hline $75-79$ & $24.64(20.82,28.46)$ & $28.29(26.69,29.89)$ & $26.23(17.04,35.42)$ & $32.70(29.07,36.33)$ \\
\hline $80+$ & $45.12(40.49,49.75)$ & $50.72(49.17,52.27)$ & $47.85(39.58,56.12)$ & $50.55(47.40,53.70)$ \\
\hline Total & 5.23 & 9.93 & 7.74 & 12.52 \\
\hline $\begin{array}{l}\text { a Disal } \\
\text { everyd } \\
\text { an appo } \\
\text { b The } 1\end{array}$ & $\begin{array}{l}\text { defined as needing he } \\
\text { ework, personal care, } \\
\text { t//running errands). } \\
\text { ion of immigrants incr } \\
2.1 \% \text { in } 2007 \text {. In } 1994 \\
\text { ence intervals given in }\end{array}$ & $\begin{array}{l}\text { erforming at least one } \\
\text { ving about inside the } \mathrm{h} \\
\text { ed from } 1994 \text { to } 2007 \text {. } \\
.6 \% \text { of women were n } \\
\text { ckets. }\end{array}$ & $\begin{array}{l}\text { or activity (preparing } \\
\text {, shopping for groceri } \\
994,17.1 \% \text { of men }\end{array}$ & $\begin{array}{l}\text { als, doing normal } \\
\text { lecessities or getting to } \\
2.5 \% \text { in } 2007 \text {. }\end{array}$ \\
\hline
\end{tabular}

